\title{
DECOLONISATION OF EDUCATION IN SOUTH AFRICA: CHALLENGES TO DECOLONISE THE UNIVERSITY CURRICULUM
}

\author{
P. Du Plessis \\ Department of Education Leadership and Management \\ University of Johannesburg \\ Johannesburg, South Africa \\ e-mail: pierredp@uj.ac.za / http://orcid.org/0000-0003-4243-6139
}

\section{ABSTRACT}

Leadership matters in the engagement and achievement of students. There is a growing demand for research in the African context as much of the research in this area has emanated from the context of western influences. Through the use of narratives, this qualitative study examines the challenges of five university heads of departments in South African universities to gain deeper insights into the leadership challenges, practices and theorising within a post-colonial context such as that which exists in South Africa. Utilising a decolonised education and a social justice leadership discourse framework, the tensions, challenges and complexities inherent in the heads of department's leadership practices are explored. Educational leaders in developing countries face problems that are different from their Western counterparts and as such, leadership practices and theorising must be contextualised. Findings support a decolonised approach to education, tensions exist in practice regarding the manifestation of social issues in universities, and the need for leadership development that is grounded in South African knowledge and experiences.

Keywords: decolonisation, leadership, curriculum, colonisation, indigenous

\section{BACKGROUND}

Nelson Mandela once said, "Education is the most powerful weapon we can use to change the world". Schools and universities are supposed to provide students with the necessary tools with which to survive the Fourth Industrial Revolution. Technology has advanced exponentially since the turn of the century, and calls have since been made for the abolition of a socioeconomic class hierarchy, which can be linked to the decolonisation of the curriculum and the culture of institutions, as well as affordable access to quality education for all, regardless of race. The decolonisation of schools and universities involves people who were previously marginalised under apartheid, choosing to embrace and recognise their own cultures, tell their own histories, study from books written by Africans, and run institutions based on values that are reflective of African culture, as opposed to Eurocentric models.

Institutions like schools and universities represent a microcosm of society, and thus, the decolonisation of such institutions will begin the process of a much broader transformation that 
will eventually affect the whole of South Africa (Le Grange 2016).

According to Dimmock and Walter (2000) leadership is an important factor in improving learning for students. There is a need for education leadership to develop outside of Western influence. University leadership has emerged as an area that requires greater attention in universities and from researchers as universities prepare students to meet the challenges of the twenty-first century, which are characterised by increasing diversity where critical thinking and collaborative skills are essential. Leadership is crucial in bringing about change in universities and improving learning outcomes for students. The Organisation for Economic Co-operation and Development (OECD) identifies university leadership as a prioritised education policy around the world, and has called for the development of university leadership frameworks that respond to current and future educational environments as countries (like South Africa) seek to adapt their education systems to the needs of a twenty-first century society. The OECD suggests that universities and schools must lay the foundation for lifelong learning while simultaneously dealing with new challenges such as changing demographic patterns, increased migration, changing knowledge markets, new technologies and rapidly developing fields of knowledge.

\section{THEORETICAL FRAMEWORK}

Under the impact of colonialism, neoliberalism and globalization, education continues to produce a system in which student disengagement, inequality and social justice continues to take place (McMahon and Portelli 2012). Educators need to make the first move if change is going to occur. Change is required to be the background to ethical grounds, which accepts, respects and embraces difference, believes in a global humanity, recognises the hegemonies that exist, and those that have helped shape history, and aims to disengage from the colonisation of knowledge (Lasky 2005). University leaders have an important role to play; they need to learn how to communicate differently, both from within the teaching profession and also in dialogue with other cultures and professions. The audience in teaching has changed from the context of a university to the citizens of the world, people from other cultures, ideologies and religions (Lasky 2005).

Colonisers have used education as a means to maintain control. Colonised history and knowledge must be disrupted in whatever space it is found,especially as it has been used as a tool to undermine indigenous people (Lopez and Rugano 2018). Battiste $(2013,616)$ argues that "no single indigenous experience dominate[s] other perspectives, no one heritage informs it, and no two heritages produce the same knowledge", and as such a decolonising approach must act as an ethical space (Joseph 2009) where people from different communities come together for reflection and dialogue in order to gain a shared understanding, and work together 
to create a shared future. Decolonising theorising calls for everybody to work together, to move beyond cultural awareness and inclusion, and re-imagine the future in our relationship with other people and cultures.

\section{THE SITUATION IN SOUTH AFRICA}

In South Africa, the curriculum and calls for free higher education became the slogans and demands contemporaneous to the time. The \#FeesMustFall (FMF) demands to decolonise the curriculum (Luckett 2016) led to heated discussions and the formation of various education forums. Black Pain emerged as a metaphor that encapsulated the embodied reality of black students on what was described as Eurocentric, racist and colonial influences.

Both Badat (2010) and the Soudien Report (2008) states that Eurocentric epistemologies are still firmly entrenched in South African education institutions, and call for intellectual spaces to be decolonised, deracialised, de-masculinised and de-gendered. Badat (2010) explains de-colonial education as followes: "The call for free, quality de-Ferris colonial education over the past years has laid bare systemic failures in national education institutions".

The student protests of 2015-2016 called for the decolonisation of higher education spaces and equal access to such spaces. Student protests are not new in post-apartheid South Africa. Through its protests across South African universities, the \#FeesMustFall movement managed to raise public awareness of the shortage of funding for higher education. Since the protests, the government has committed to providing additional funding to the student aid scheme. The protests served as an effective tool of communication, although questions continue to be raised about the acts of violence associated with the protests.

On the whole, the \#FeesMustFall movement was lauded for its achievement in raising awareness of the funding crisis at institutions in South Africa. The movement achieved a number of positives at tertiary education institutions, including the renaming of university buildings and schools, curriculum transformation, and the insourcing of general workers. The protesting students also initiated the discussion on decolonised education, which was carried over into discussions on decolonised education in South African schools .

The South African education system continues to navigate a colonial past within the context of global shifts and social changes. Many elements of South African education have remained untouched or unchanged. This is seen in the way that the curriculum is structured in schools, access to quality education, and the fact that many South African schools are still structured according to a class system. Wa Thiong (1998) refers to this and suggests the erasure and suppression of South African languages is a deliberate effort to maintain the status quo and keep a colonial structure in place. The South African education system continues to colonise 
the spaces in which learners learn (Ferris 2017) and as argued by Dei (2000), fails to critique colonial liturgies present in most school curriculum and practices, which impact on the creativity of educators.

Social justice leadership involves moral dialogue, which is concerned with the need to balance academic achievement and encourage justice (Lopez 2016). Social justice leadership is about advocacy and change, where leaders in educational institutions take bold actions to influence and change educational policies (Lopez 2016) so that marginalised learners can be better served. We need university leaders that can create space for reconceptualising, rethinking and to understand that no one notion of social justice can be applied universally.

Decolonising education calls for a Eurocentric consciousness to be disrupted, and notions of meritocracy within education and society that have privileged some, to be challenged. Abdi $(2012,12)$ suggests that decolonising educational praxis disturbs "the structural as well as the functional coherence of official knowledge and learning discourses and their selectively dysfunctional scribbling of totalizing Eurocentric metanarratives". Within South Africa, the experiences and knowledge of former colonised people must be foregrounded, their traditions must inform and shape practice. Decolonising theories and documents on social injustice, gives voice to subjugated knowledge, creates space for the voices of the silenced to be expressed and listened to, and challenges racism, colonialism and oppression (Luckett 2016), and therefore, has convergence with those who advocate for socially just leadership. If we are to move education in South Africa forward, alternative ontological and epistemological ways of knowing must be centred, understood and practised. In this, both scholars and practitioners must join forces to bring theory and action together.

The education system continues to navigate a colonial legacy within the context of global shifts and societal changes. In South Africa many of the structural elements of the education system have remained unchanged. The effects of colonisation on South Africa's education system are still seen in the prevalence of centralisation, standardisation, and a system that perpetuates South Africa's existing class structure and access to quality education (Lopez and Rugano 2018).

The focus on challenging injustices in education and society in South Africa creates a convergence between social justice leadership and decolonising education as theoretical framework that guides this research. Social justice leadership involves ways of thinking about practicing leadership that challenges university leaders to seize upon the potential that diversity offers, challenging dominant discourse and knowledge. Social justice leadership is about advocacy and change (Lopez 2016), where university leaders take bold decisions and actions to influence and change educational policies so that students who are at the margins can be 
better served.

Heads of departments play a virtual and multifaceted role in setting the direction for universities and faculties. Evidence suggests that second only to the influences of classroom instruction, university leadership strongly effects student learning. The role of the head of department (HoD) has swelled to include a staggering array of professional tasks and competencies: HoDs are expected to be creative and critical thinkers, instructional and curriculum experts, assessment experts, disciplinarian experts and curriculum experts of various policies, and a budget analyst. The demands of the job have changed so that traditional methods of preparing university leaders are no longer adequate to meet the leadership challenges posted by universitiess. Many aspiring leaders are too easily admitted into and passed through the system, without evidence of their leadership capacity on the basis of their performance, rather than on a comprehensive assessment of the knowledge, skills and dispositions needed to successfully lead schools. In this regard, HoDs are struggling to be curriculum experts in the university and are led by staff in the management of thereof. HoDs without proper knowledge of the curriculum will always have problems in implementing the changes of a decolonised curriculum. In many instances, the heads of departments in universitiess are leading curriculum management and seldom have the expertise or knowledge to "decolonise" the curriculum (Waghid 2014).

\section{METHODOLOGY}

The study employed qualitative research with a narrative approach that examined the challenges for university leadership to decolonise their approach to the curriculum in South African universities. Qualitative research methods involve the systematic collection, organisation, interpretation of textual material derived from talk or observation (Malterad 2001). It is used in the exploration of meanings of social phenomena as experienced by individuals themselves in their natural context. Interviews were undertaken with five HoDs (decoloniality conversations). According to Neuman (1997), key to qualitative research is the social context and issues concerning power relations and inequality, including a transcendent perspective towards social change. An aspect of the article is a discursive content analysis of the interview and decolonisation discussions held with the respective HoDs. Discourse analysis is useful in probing texts and decisive practices to highlights social inequality, who dominates and has power, and the central role of language (Joseph 2009).

The intent of this article is to gain special insight through first-person accounts of the ways in which individuals experience faculty leadership in universities where the decolonisation of the curriculum is a challenge. In this fashion, the study views the question of university 
leadership practices through the experiences of other HoDs and the people who observe their work.

According to Stake (2003), the most unique aspect of case study research lies in the selection of the particular cases to be studied. Because the goal is to select those cases that provide the least opportunity to learn, qualitative researchers often use purposeful sampling (Creswell 2013). With purposeful sampling, the researcher purposefully selects those individuals and sites for study that hold the greatest potential for providing a better understanding of a study research problem and central phenomenon. Thus, the research question is: "What are the challenges faced by the university leaders to decolonise the curriculum in faculties?"

For the study, a criterion-based methodology was used. The subject pool consisted of all the HoDS in two faculties. Fourteen HoDs were invited to take part through a criterion-based methodology. The sample was narrowed to five HoDs.

The case study approach to qualitative analysis involves a specific way of collecting, organising and analysing data (Stake 2003). Standardisation and open-ended interviews were the primary sources of data collection. Interviews were conducted with each of the five HoDs. According to Ladson-Billings and Tate (1995), the goal of case records is to take the reader into a case situation, in this instance the working lives of each of the five HoDs.

The coding system was very useful in distinguishing between the interviews at the different faculties. I used the coding of D1-D5, indicating that D1 refers to HoD1 and D5 to HoD 5.

Data was collected, analysed, coded and sorted into themes. For this study, participant interviews served as the primary source of data. Data analysis focussed on economic thematic similarities and differences in leadership challenges with regard to decolonising the curriculum among the six principals involved in the study.

The interviews were received and references to specific leadership challenges were highlighted and identified. A total of 49 citations were identified among the five interviews. For data verification and authentication purposes, each leadership challenge had to be cited by at least three interview participants in order to be recognised for the study. Table 1 lists the most frequently referenced challenges.

Table 1: Most frequently cited leadership challenges

\begin{tabular}{|l|c|}
\hline \multicolumn{1}{|c|}{ Challenge } & Citations \\
\hline No knowledge of decolonisation & 17 \\
\hline Reluctance to change the curriculum & 13 \\
\hline
\end{tabular}




\begin{tabular}{|c|c|}
\hline Challenge & Citations \\
\hline No connection with realities of students & 09 \\
\hline Problem with White perspective & 06 \\
\hline Lack of dialogue & 04 \\
\hline Total & 49 \\
\hline
\end{tabular}

The research sample was small, and therefore, I cannot generalise my findings across all departments. Thus, the study clearly indicated that HoDs find decolonisation a complex task. The following themes were identified during the interviews and discussions:

1. No knowledge of decolonisation

2. Reluctant to change the curriculum

3. No connection with realities of students

4. Problem with White perspective

5. Lack of dialogue

\section{DISCUSSION OF FINDINGS}

\section{No knowledge of decolonisation}

After 26 years of democracy in South Africa, our schools and universities tend to offer a view of the country that is rooted in colonial and apartheid thinking. The curriculum in universities remain largely Westernised, more of a white European view of what should be included into our curriculum (Le Grange 2016).

"The problem is many lecturers do not know what decolonisation entails. Another fact is that many lecturers do not make an effort to find out about other cultures and civilisations." (D3 - HoD).

So the lived experiences of black students are not reflected in classrooms.

Sociologists of education argue that "curriculum" is a highly ideologically-helped discourse. This means that it includes implicit ways to knowing, ways of doing, and ways of being, as well as content. Lecturers in general think about decolonising the curriculum from one angle, changing the content of what they teach; that if they add Africa-based authors to a reading list it will be enough. The problem is that they do not shift the tasks required to engage with the literature, and learners remain alienated and marginalised.

Lecturers do not engage in different ways of teaching, and are ignorant to what decolonial practices might bring to the classroom. 
The transformation of the post-apartheid system of education requires the rebuilding of the fibre of the nation whilst taking full cognisance of the past. Quality education for all requires new capacities to be built around literacy, critical thinking and conceptual imagination. This calls for a radical conception of the very building blocks of education (Block and Corona 2014).

"Those interested in decolonising the classroom must take a first, crucial step in personal commitment to political change." (D2).

"If we deny the racial nature of politics, both inside or outside the classroom, is to perpetuate the inequities created by colonisation." (D2).

Principals find it hard to expand on decolonisation ideas where staff are divided in their ideas of decolonisation. One cannot claim to be against racism while acting as a functionary for a colonial and racist system, when benefitting materially while doing so (Phillips and Whatman 2007).

"I am in [sic] teaching for 13 years, and I have yet to encounter a lecturer who openly espouses racism." (D4-HoD).

The problem of not knowing what decolonisation entails is to ameliorate the deep damage caused by colonisation and racism. To decolonise the university/classroom, one must examine oneself and to let go of the disingenuous notion of objectivity in the classroom, of maintaining political neutrality, of seeing all sides and positions as having equal impact on marginalised groups. To start learning about decolonisation is to understand your job as providing students with the means of grasping that their difficulties and struggles stem from an identified inequality system and culture, as well as ways of resisting and subverting such systems.

"Lecturers do not see and do not challenge systemic oppression and acknowledge the collective of marginalised groups." (D4).

Another problem lies in the fact that "lecturers are taught in their training to envision themselves as doing good, and still reinforce and perpetuate the colonisation and racism that damage students" (D3-HoD). Instead of envisioning students as individuals in need of the tools required for self-improvement, politically conscious lecturers understood that the suffering of marginalised students is a result of an inequitable system. To empower students on the margins means much more than guiding individuals to a sanctioned academic success. Individuals are empowered when systems are altered to shift power towards the groups to which they belong. To empower people from marginalised groups means to disrupt the current balance of power, 
something the powerful invariably resist. Politically conscious individuals withstand such a backlash.

\section{Reluctant to change the curriculum}

The decolonisation projects needs to encompass more than just changing the curriculum. How things are taught and lectures' attitudes to this process matters just as much. While adding literature from the African continent and the global South is important in decolonisation discussions, it is by far not enough. The attitude of university staff towards the content used in the curriculum is critical.

"I am sitting with an older staff, who still belief [sic] that the old topics in the curriculum is [sic] fine". (D1).

In a study conducted on indigenous education in Queensland, Phillips and Whatman $(2007,3)$ argue that the process of decolonising any education curriculum requires "in the first instance, attending primarily to the reform of those colonising spaces in which such teaching takes place before any specific transformation of the curriculum itself is carried out".

By implication, for educators in South Africa to address the increasing claims of Indigenous African Knowledge Systems (IAKS) as a means of assessing and resisting or transforming a colonised curriculum may be underscored (Waghid and Hibbert 2018) by their willingness to engage in both the curriculum and their pedagogies critically, self-reflexively and imaginatively.

This presents a massive challenge. If the university curriculum prescribes new topics that focus on decolonisation, what are the attitudes of lecturers/staff towards buying into the new ways of thinking?

\footnotetext{
"Many of my staff still assume that what is taught (Western knowledge) constitutes to [sic] only basis for higher thinking." (D5).

"My department let me discuss how we can decolonise some subjects in my department, but when it comes to implementation, they are reluctant to do it." (D2 - HoD).
}

The question must be asked whether lecturers are willing to change? Are they ready to fundamentally transform as university staff? In other words, are lecturers ready to decolonise their minds and set out on new ways of thinking about Africa, the continent, and what we need to teach our students? Lecturers must at least be literate about the historical injustices and diversity within their respective disciplines or subjects. Universities will not decolonise 
overnight, but the process must start. Lecturers who fear decolonisation must change for this important shift to occur (Dei 2000).

Universities need to incorporate epistemic perspectives and knowledge from the African continent.

"Lecturers think that if we decolonise we will move back to the nineteenth century." (D3 - HoD).

University staff ignorance of decolonisation and a reluctance to engage with such theory to educate themselves, is an emergent problem and challenge for leadership in universities.

"There is often little willingness to listen, engage and grapple with questions on decolonisation." (D4).

Staff tend to fail to understand that colonisation and colonialism was a planned, calculated system of oppression and imperialism.

Staff want definitions of different concepts, they do not know how to decolonise their subjects, how to change the literature they use for teaching, if decoloniality was meant to improve the system. Again the discourse of ignorance (reluctance) of spoon-feeding, "failing to educate themselves by reading up on decoloniality." (D3 - HoD).

IT $[\mathrm{t}]$ seems as if the "staff lack the urgency and the consciousness to know that they can teach themselves by simply reading up on the concepts of coloniality and decoloniality" (D1).

When asked if they know the embodiment of the studentss in their respective classess, it was clear that there was an ignorance about the real lives of students (Luckett 2016).

"No, we do not know what a typical day in the students' lives really means, and we are so crowded with curriculum matters, that we don't even think about it." (D1 - HoD).

"We see them going to the feeding scheme for lunch and sometimes thinking [sic] where they are coming from." (D4 - HoD).

Universities need to improve their communication with all students. There are voices to be heard; opportunities must be created to listen to them.

"Yes, I think we are guilty, and it gives a negative reflection of our school that we invite these [sic] into the school, but never really listen to learners." (D4).

University staff must create open opportunities to learn from students, and not keep a blind eye to grow and step into the world of students. 


\section{No connection with realities of students}

Universities need flexible and agentic lecturers/staff who are connected to the realities of students, and the colonising approach is lacking in locating alternative voices to inform the university curriculum (Hoppers 2001). Within our schools and universities, decolonisation of the curriculum calls for the dismantling of Eurocentric epistemologies that continue to dominate (Zeleza 2009), and the reawakening of indigenous knowledge.

"I am a HoD for the past 10 years, and I haven't seen any big changes, if any towards the realisation of decolonising the curriculum. It is still based on Westernised and apartheid views." (D1).

For curriculum change to happen in teacher education, there has to be a deliberate shift away from a position of instrumentalism and reaction, towards a deep intellectualism of the curriculum (Mbembe 2016). Change and decolonising of the curriculum necessitates looking at the curriculum in terms of relevance to one's context and understanding oneself and others (Mahabeer 2018). Decolonising the curriculum is one thought linked to the concept of ubuntu that celebrates the oneness of the self and others in creating the stimulus for a more humane world for all. It is, therefore, important for lecturers to have knowledge of where their learners come from, and what their circumstances and realities are.

"I don't think many of my staff, although we discuss it regularly, have any background of where the students are coming from, their culture, language and their everyday activities." (S2 - HoD).

If universities want to bring about transformation in South Africa, as well as in Africa, they need to profoundly transform the way they think about the curriculum, what and how they teach, and connect within the realities of their students. The question arises: whose knowledge counts and whose reality? These are questions that should be considered when reconstructing the curriculum.

"I think it will help if universities put more emphasis on decolonisation of the curriculum. If students come to teach in their first year they are more ready for changing the curriculum and to assist the older thinkers of the staff." (D3 - HoD).

"If we connect better with our students it will make us better human beings. If we know our students then I believe every student has the potential to develop, as we will be better equipped to understand the social, historical and economic circumstances." (D5).

The objective of humanist education moves beyond the intellectual and cognitive, it is 
concerned with the inner world of the individual, and educates the whole person for human development (Aloni 2007).

A critical review of the whole curriculum should extend beyond mere reflection, it should listen to the lost cultures, histories and values of indigenous people.

\section{Problem with White perspective}

Decolonisation is not merely a matter of political independence (Waghid, 2004). To claim that colonial thinking stops having an impact on decolonised countries and its citizens, is to misunderstand how deeply colonial thought affected colonised countries and their citizens. To overcome the legacy of colonialism, it is also necessary to decolonise the intellectual landscape of the country in question, and ultimately decolonise the mind of the formerly colonised (Oelofsen 2015).

"As the HoD of a big department with a multicultural staff, it is not easy to harmonise the thinking of black and white staff member[s], to think the same about matters in the curriculum or things one wants to change." (D4).

In South Africa the historical legacy and classification of the population according to "race" has resulted in a strong identification by individuals with their ascribed racial groups. As a result, it is difficult to imagine that race does not continue to play a central role in the current South African political landscape (Ndlovu-Gatsheni 2013). Racial identity is still central to how most people think of themselves, even if certain individuals in the country claim not to think of themselves in this way.

"In our department the different races are still clinging onto their historical pasts and it is difficult to change anything if the different parties do not want to meet midway to discuss mutual similarities or even differences that we need to work on. So white is white and black is black." (D3).

The white coloniser needs to engage in and be transformed by a pedagogy that requires the learning of skills, including an understanding of the difference between prejudice and racism. As such, there is no such thing as reverse racism in a white supremacist society, as racism depends upon having the power to institutionalise one's own prejudices. It is also understanding the difference between equality and sameness (Lave and Wenzer 1991). Under conditions of domination, movement towards equality does not entail treating everyone the same, but rather privileging those perspectives and practices that counter domination. This includes not giving equal weight to white attendance in the classroom. 
It will take time to change the perceptions of staff regarding decolonisation, especially those who have been taught according to Western frameworks, and to find sources to fundamentally re-shape the curriculum.

\section{Lack of dialogue}

"Another problem is that staff do not engage in proper dialogue regarding decolonising the curriculum, or which aspects, themes or topics must be decolonised." (D4 - HoD).

Le Grange (2016) argues that decolonisation of the curriculum entails a shift from Western/Eurocentric individualism and universalism to an ubuntu-infused curriculum, which acknowledges the independence of humans and the more-than-human world. An ubuntuinfused African-centred curriculum does not necessitate the destruction of dominant knowledge systems, but rather demands a recentering or integration of African knowledge systems into dominant epistemological discourses. According to Naude (2017), knowledge does not necessarily have to emanate from Africa, but it must address the African reality. It merits reiteration that the decolonisation of the curriculum requires dialogue and engagement, which "forces the inclusion of a grassroots perspective into education research and practice" (Higgs 2011). Meaningful engagement and dialogue with those who still suffer from colonial oppression is crucial, and the responsibility to respond rests not only with those who still suffer from colonial oppression, but also with those who remain at its helm.

"We must try to workshop the decolonisation aspect in our department. Maybe to get an expert to talk to us on how to address this in our department and curriculum. We do not engage enough." (D5 - HoD).

Dastile (2013a) states that historically Westernised subjects should be de-mythologised and historical and contemporary theoretical resources that challenge familiar boundaries of subjects should be recovered.

"With more dialogue and engagement among staff and senior management of the university, we can move how it impacts on the curriculum." (D3 - HoD)

Engagement and dialogue will initially occur outside of the formal curriculum, but once lecturers become better informed, there will be a stronger probability that this will become part of formal discussions on curriculum matters and conversations. A commitment to social justice highlights the need for decolonisation. 


\section{RECOMMENDATION}

We have to fundamentally rethink our curriculum in order to move South Africa to the centre of teaching and learning. There is a need to gain knowledge regarding the African continent, its histories, cultures and civilisations, and textbooks must reflect indigenous knowledge. South African universities must start asking deep questions that examine what decolonisation might look like in their teaching and how to achieve it.

In order to understand ourselves in the West, whatever our heritage might be, there is a need to acknowledge the legacy that colonialisation of much of global South Africa (Pinar 2012) continues to have on how we understand our students and teach them about the world.

Previously disadvantaged groups, who are still suffering oppression within the university climate, are asking to be seen, acknowledged, heard, consulted and respected (Dastile 2013b). University leaders must be seen to be willing to respect these groups, to sit in uncomfortable spaces and engage with difficult emotions felt by people.

Departmental leaders need to engage in conversations with staff to decolonise classrooms and to make changes; diversify materials and content; teach learning outcomes that address power and social justice; design assessments, which allow for diverse learners to demonstrate mastering in diverse ways; embrace diverse language usage in interactions, and involve teachers and senior staff at institutional, local and national levels in the quest for equality.

Social issues should be linked to academic content (Biesta 2016). Lessons should use examples based on South African history as a teaching strategy to highlight social justice. In the classroom, staff should strive to define decolonisation, take responsibility for it, foster openness, and promote African centrality. As soon as lecturers become informed and familiar with social issues through extensive exposure to lessons and deep discussions, they will have more courage to engage with students and give them a voice.

\section{CONCLUSION}

The aim of this article is to gain insights on the challenges leadership faces in understanding and implementing decolonisation as part of the curriculum. Despite efforts made by HoDs to start the process, initiatives aimed at creating a good platform from which to respond to global and national changes are still far from ideal. The role of leadership in universities is a good starting point from which to deepen an understanding of decolonisation. The narratives of the participants illuminate some of the complexities, tensions and challenges that leadership continue to face in South Africa. This cannot be understood outside the context of South Africa's colonial past and the manner in which education structures and practices continue to dominate colonised notions of education, influenced by neoliberal practices. Much work lies 
ahead for leaders in Africa, especially South Africa, and from the West to collaborate respectfully, to disrupt colonial legacies that are ever present in Africa. They must collaborate on theorising leadership policies and practices grounded in a decolonising and social justice leadership framework, which focuses on African histories and knowledge systems. Decolonising education and social justice leadership offers frameworks to theorise leadership in developing countries.

\section{REFERENCES}

Abdi, A. A. 2012. Decolonising philosophies of education. Rotterdam: Sense Publishers.

Aloni, N. 2007. Enhancing humanities: The philosophical foundations of humanistic education. Dordrect, the Netherlands: Springer.

Badat, S. 2010. The challenges of transformation in higher education and training institutions in South Africa. Paper commissioned by the Development Bank of Southern Africa. April 2010.

Battiste, M. 2013. "Decolonizing education: Nourishing the learning spirit." Journal of Education Research 60(3): 615-618.

Biesta, G. J. J. 2016. Beyond learning: Democratic education for a human future. New York, NY: Routledge.

Block, D., and V. Corona. 2014. "Exploring class-based intersectionality." Language, Culture and Curriculum 27(1): 27-42.

Creswell, J. W. 2013. Qualitative inquiry and research design: Choosing among five approaches. $3^{\text {rd }}$ Edition. Thousand Oaks, CA: Sage.

Dastile, N. 2013a. "Beyond Euro-Western dominance: An African-centred decolonial paradigm." Africanus 93.

Dastile, N. P. 2013b. "Power, knowledge and being: Decolonial combative discourse as a survival kit for Pan-Africanists in the $21^{\text {st }}$ century." Alternation 20(1): 105-134.

Dei, G. 2000. "Rethinking the role of indigenous knowledge in the academy." International Journal of Inclusive Education 4(2): 111-132.

Dimmock, C., and A. Walker. 2000. "Cross-cultural values and leadership." Management in Education 14(3): 20-27.

Drinkwater, M. 2014. "Decolonizing Education: A rule for the arts and cultural proxies: Lessons from primary schools in Maasailand, Southern Kenya." Unpublished thesis.

Ferris, L. 2017. "Preparing SA for free, quality decolonial education.” News24 July 24, 2017.

Higgs, P. 2011. African philosophy and the decolonisation of education in Africa: Some critical reflections. Education Philosophy and Theory 1.

Hoppers, C. A. 2001. "Indigenous knowledge systems and academic institutions in South Africa." Perspectives in Education 19(1): March 2001.

Joseph, T. R. 2009. Decolonising the curriculum transforming the University: A discourse perspective. London: Sage.

Ladson-Billings, G., and W. F. Tate. 1995. "Towards a critical race theory of education." Teachers College Record 97(Fall).

Lasky, S. 2005. "A sociocultural approach to understanding teacher identity, agency and professional vulnerability in a context of secondary school reform." Teaching and Teacher Education 21(8): 899-916.

Lave, J., and E. Wenzer. 1991. Situated learning: Legitimate peripheral participation. New York: 
University Press.

Le Grange, L. 2016. "Decolonising the university curriculum: Leading article." South African Journal of Higher Education 30(2): 1-12.

Lopez, M. 2016. Decolonizing primary English language teaching. New York: University Press.

Lopez, A. E., and P. Rugano. 2018. "Educational leadership in post-colonial contexts: What can we learn from the experiences of three female principals in Kenyan Secondary Schools." Education Sciences 8(3): 99.

Luckett, K. 2016. "Curriculum contestation in a post-colonial context: A view from the South." Teaching in Higher Education 21(4): 415-428.

Mahabeer, P. 2018. "Curriculum decision-makers on decolonising the teacher education curriculum." South African Journal of Education 38(4).

Malterad, K. 2001. "Qualitative research: Standards, challenges and guidelines.” The Lancet 358(9280): 483-488.

Mbembe, A. J. 2016. "Decolonising the university: New directions." Arts and Humanities in Higher Education 15(1): 15-29.

McMahon, B., and J. Portelli. 2012. Student engagement in urban schools: Beyond neoliberal discussions. Charlotte, NC: Information Age.

Naude, P. 2017. "Decolonising knowledge: In what sense is an African ethic possible." Inaugural lecture, Stellenbosch University.

Ndlovu-Gatsheni, S. J. 2013. "Why decoloniality in the $21^{\text {st }}$ century?" Thinker 48(2013): 10-15.

Neuman, N. L. 1997. Social research methods. Qualitative and quantitative approach. Boston: Allan and Bacon.

Oelofsen, R. 2015. "Decolonisation of the African mind and intellectual landscape." Promina 16(2): 130-146.

Phillips, J., and S. Whatman. 2007. "Decolonising preservice teacher education: Reform at many cultural interfaces." Paper presented at the American Educational Research Association meeting. Chicago, USA.

Pinar, W. F. 2012. What is curriculum theory? $2^{\text {nd }}$ Edition. New York, NY: Routledge.

Soudien, C. 2008. Transformation in higher education: A briefing paper. Development Bank of South Africa.

Stake, J. 2003. The art of case study research. Thousand Oaks, CA: Sage.

Waghid, Y. 2004. "Revisiting the African-Africana philosophy of education debate: Implications for university teaching." Journal of Education 34(1): 127-142.

Waghid, Z. 2014. "Education for social justice through sustainable development, economic development and equity." South African Journal of Higher Education 28(4): 1448-1463.

Waghid, Z., and L. Hibbert. 2018. "Decolonising preservice teachers' colonialist thoughts in higher education through defamiliarisation as a pedagogy." Education Research for Social Change. Special Issue 7: 60-77.

Wa Thiong, N. 1998. “Decolonising the mind.” Diogenes 184 46(4) Winter: 101-104.

Zeleza, P. T. 2009. "African studies and universities since independence: The challenges of epistemic and institutional decolonization." Transition 101: 110-135. 